\title{
Facebook Use through Mobile Devices by Teenagers in Albania
}

\section{Elda Tartari}

\author{
PhD Candidate, "Aleksander Moisiu" University, Durres
} eldatartari@gmail.com

\section{Doi:10.5901/jesr.2014.v4n4p88}

\begin{abstract}
The purpose of this study is to assess the perception and use of social network ( Facebook) by teenagers in Albania through mobile devices and to highlight its positive and negative impacts. Research method is descriptive. A questionnaire was designed and the sample taken was of age between 13-18 years old. The results showed an intense use of the social network, Facebook. The respondents access more often in their profiles but do not make posts. Positive impacts that have been are: strong relationship with family, relatives, friends and much more involvement in social, political and cultural activities whereas the negative impact were result of lack of studying and the long time they spent in this network. The respondents are mainly taken from several major cities in Albania, so we cannot make a generalization for the whole country. This research aims to show the importance that the social network, Facebook has on teenagers.
\end{abstract}

Keywords: social network, Facebook, mobile devices, teenager/s, Albania

\section{Introduction}

Today the Internet and social networks in particular are more impactful and effective than many important elements of society such as family or school. The Social Networking Websites has become an international phenomenon in the past several years. What started out as a hobby for some computer literate people has become a social norm and way of life for people from all over the world (Boyd, 2007).

These tools are features of social network sites (SNS), such as Facebook, Instagram, MySpace, Google+, SNS are part of a suite of Web applications, also called social media, which utilize Web 2.0 principles. The term Web 2.0 principles defines websites that are designed to: rely on the participation of mass groups of users rather than centrally controlled content providers, aggregate and remix content from multiple sources, and more intensely network users and content together (O'Reilly, 2007). The use of Web 2.0 technologies in every aspect of our lives has led researchers to consider the potential of social network use in education (Tılfarlığlu, 2011). Teenagers and young adults have especially embraced these sites as a way to connect with their peers, share information, reinvent their personalities, and showcase their social lives (Boyd, 2007). Facebook is the most visited site in Albania (Alexa.com 2014). Adolescents use social media in large numbers. (Albanian Facebook Statistics, 2014)

I use the terms youth, teenagers and adolescents because it's difficult to define categories such as children, adolescent and young adults concrete terms. National studies often define teenagers as between the ages of 12-17 (see Lenhart et al., 2010). However, Ito et al. (2009) observe that terms such as children, adolescent, and yang adults are socially and culturally constructed labels. In their case studies of youth and media they define children as less than 13 years of age, teenagers and adolescents as between 13-18. This study is going to include adolescent between the ages of 13-18.

\subsection{What are social network sites and how do adolescents use them?}

When teenagers join a site like Facebook they first create a personal profile. These profiles display information such as one's name, relationship status, occupation, photos, videos, religion, ethnicity and personal interests, these three features: profiles, friends, traversing friend list represent the core, defining characteristics of SNS.

Facebook is employed mostly to keep in touch with people and to know them better (Joinson, 2008). Facebook was also found to be frequently used to maintain distant relationships, as it allows for immediate communication between users who are geographically far (Golder et al., 2007) Social networking features are increasingly integrate into other types of media tools and online communities. Sonia Livingstone (2008) notes that SNS invite "convergence among the hitherto separate activities of email, messaging, website creation, diaries, photo albums and music or video uploading and downloading". (394).

There are even researchers contending that social networking sites have potential to change educational system 
radically, motivating students for better learning rather than being passive attendees of a classroom (Ziegler, 2007). Mason (2006) claims that social networking sites have enough capacity for a good "official" education matching the social contexts of learning and promoting critical thinking in learners (Mason, 2006). Many scholars suggest that students learn in new ways using social media and that educator should embrace these new platform (Ito et al., 2009; Jenkins, 2006). However, many researchers also found a positive association between use of internet and SNS and academic performance of the student users. Students, using internet frequently, scored higher on reading skills test and had higher grades as well (Linda et al., 2006) but most school district block access to SNS (Lemke, Coughlin, Garcia, Reifsneider, \& Baas, 2009) for the safety of students.

\subsection{Research questions}

- Do Albanian's teenagers have interest in the social network called Facebook?

- Do they use social network by phone?

- Do they spend more time on Facebook?

- Do they use social networks as a teaching tool?

\section{Methodology}

The quantitative method is used in e descriptive way in this study. The study involves 121 respondents which were interviewed by a questionnaire designed for these case. This questionnaire had the intention to measure the way of usage of the Facebook by the teenagers, according also to the main components Facebook was built. The teenagers that participated in this study were: $74.4 \%$ females and $25.6 \%$ males. These teenagers are from the cities Tirana and Durres

\subsection{Instruments}

The instrument was organized into two sections. The first section gathered demographic data, as well as data on spending time and via phone and computer use while the second section collected data for the elements that make up Facebook. This section was organized by Likert scale. They must show the frequency of activities related to Facebook with the following statements $(1=$ more often, $2=$ often, $3=$ some time, $4=$ rarely, $5=$ never $)$.

\section{Findings and Discussion}

\subsection{Analysis of the Quantitative Data}

121 teens are surveyed for this study. 115 of them has now an active account in Facebook and 6 of them are not present at this social network. The reason why they did not open an account in Facebook was because they had no interest. Teenagers who had the account access during the day: only once $=5.2 \%, 2-3$ times $=40.9 \%, 4-5$ times $=24.3 \%$ and more than 6 times $=29.6 \%$. So as seen, adolescents access many times to the accounts during their day.

Social network could be accessed by their personal computers (PC) or by mobile devices. Teenagers that participated to this study were split between these devices; 89 of them use mobile devices, generally they smartphone, and PCs do access their accounts, 19 of theme use only the smartphones and 7 of them use only the PC. The usage of Facebook by a mobile device also affects the time spending. At the Table 1, we can see the time that they are spending in the social network. $19 \%$ of them spend less then 30 minutes in FB; $23.7 \%$ of them remain in the network one hour; $35.1 \% 2$ hours and $21.9 \%$ remain more than 3 hours there.

Table 1. The usage time of Facebook

\begin{tabular}{|c|c|c|c|}
\hline & Time in Facebook & Frequency & Valid Percentage \\
\hline & Less then 30 minutes & 22 & 19.3 \\
\hline & 1 hour & 27 & 23.7 \\
\hline Valid & 2 hours & 40 & 35.1 \\
\hline & More than 3 hours & 25 & 21.9 \\
\hline & Total & 114 & 100.0 \\
\hline
\end{tabular}




\subsection{The usage of FB by teenagers for communication}

To measure this component of FB there were constructed 9 questions. These questions gathered information about the communication through private messages and voice communication, status posts, comments below the statuses and photos, poking friends and video posts. The results gathered showed that $12.3 \%$ of teenagers used FB very often for communication; $54.4 \%$ of teenagers use often the FB for their communication; $33.3 \%$ used that too rarely. There is a difference in the usage of the social network between males and females. According to the correlation of these variables is seen that the females use the FB to communicate more than the males. This communication has positive impact in their lives and strengths the relationship between friends, family members etc.

\subsection{The usage of FB as a study source}

To measure this component were constructed 7 questions which gathered info for study usage, search for information, and ask for help and exchange the homework, conversation in a foreign language as a practice, sending of links and pages for more information about the school and study in general. According to the analysis that came out of the research we have these percentages: $43.9 \%$ of the asked teenagers use very often the Facebook as a learning-study tool; $36 \%$ use it often, $20 \%$ use that very rarely during the study process. Between gender and the use of social networking there is a weak positive correlation $(r=0.2, p<0: 02)$. On the other hand viewed a weak negative relation between spending time and use the FB as a teaching resource by Pearson $(r=-0.1, p<0: 05$. As e result, we can say that the social network is used widely by the teenagers to help their study process.

\subsection{The usage of FB for entertainment}

The social network give the opportunity to be engaged and entertained. To measure the usage of this component there was constructed a set a questions that give information about these elements: listening of the music, reading poetry, reading and sharing of quotes, playing games in FB, and watching different types of videos. According the analysis, $35.1 \%$ of the teenagers part of the survey use Facebook very often for these elements, $47.4 \%$ use that often and $17.5 \%$ use Facebook rarely for these entertainment tools. There is a negative relationship between expenditure of time and entertainment in FB which interpreted statistically $(r=-0.3, p=0: 01)$.

As it is seen, a considerable part of their time is used for entertainment, which has positive effects in their psychological condition.

\subsection{The usage of Facebook for promotion and information}

Promotion and information are to important element in the usage of Facebook. For these components there were constructed a set of questions as the location posting, and the posts of the teenagers about their achievements and personal success. The conclusions showed that $42.1 \%$ of the teenagers used Facebook very often for promotion of their self, $31.6 \%$ used it often and $26.3 \%$ used it rarely.

As we can see, the teenagers has the open tendency for self-promotion in the social networks. At the other side, they use FB to take general information or news from showbiz and also information for socio-cultural activities in their areas and beyond. According to the findings, $68.7 \%$ of the teenagers use FB very often for general information, $16.5 \%$ use it often and $14.6 \%$ use is rarely. The Facebook is now not only a social page, but also a media for these young people that generally do not read traditional media.

\section{Conclusion}

The main aim of this study is the measurement of usage of the social network Facebook by Albanian teenagers through their mobile devices and PCs.

According to the findings, 95 percent of these teenagers have an account in Facebook and access that regularly during the day. They have a very high interest to be part of this social network. There is a wide usage for communication and voice calls. Also they us it for entertainment, information self-promotion etc. These elements play an important role in the life of these teenagers and have impact in their personal development.

Also a positive finding is that teenagers use Facebook as a study-learning source where through communication with their friends, teachers and family members they can help their learning process. 
Positive impacts that have been are: strong relationship with family, relatives, friends and much more involvement in social, political and cultural activities whereas the negative impact were result of lack of studying and the long time they spent in this network. But we cannot generalize this study for all the teenagers in Albania, because the main area that was studies is the capital Tirana and the city of Durres.

Empirical studies on the effects of SNS are not present in Albania. There should be more studies in this field. They are necessary for informing the Albanian society, parents and the teachers, because there is a discussion about the usage of the social networks by the teenager in the country.

\section{References}

Albania Facebook Statistics. Retrieved March 21, 2014 from http://www.socialbakers.com/facebook-statistics/albania

Boyd, Danah M, (2007) Social Network Sites: Definition, History, and Scholarship. Retrieved April 26, 2014 from http://www.danah.org/papers/JCMCIntro.pdf

Ito, M., Baumer, S., Bittanti, M., Boyd, D., Cody, R., \& Herr-Stephenson, B. (2009). Hanging out, messing around, and geeking aot: Kids living and learning with new media. Cambridge, MA: MIT Press

Jenkins, $H$ (2006). Confronting the challenges of participatory culture: Media education for the 21st century. Chigago: The John D. and Catherine T.MacArthur Foundation.

Lemke, C., Coughlin, E., Garcia, L., Reifsneider, D., \& Bass, j., (2009). Lidership for web 2.0 in educatin: Promise and reality. Culver City. CA: Metiri Group

Lenhart, A., Purcell, K., Smith, A., \& Zichkuhr, K. (2010). Social media \& mobile internet use among teens and young adults. Washington, Dc: Pew internet \& American Life Project.

Livingstone, S. (2008) Taking risky opportunities in youthful content creation: teenagers' use of social networking site for intimacy, privacy, and self- expression. New Media \& Society, 394-411.

O' Reilly, T. (2007).What is web 2.0: Design patterns and business models for the next generation of software. Communication \& Strategies, $65,17-37$

Tılfarlıoğlu, F. Y. (2011). An International Dimension of the Student's Attitudes towards the Use of English in Web 2.0 Technology. The Turkish Online Journal of Educational Technology, 10:3.

Top Sites in Albania. Retrieved March 21, 2014 from http://www.alexa.com/topsites/countries/AL

Ziegler, S. (2007). The (mis) education of Generation M. Learning, Media and Technology, 32, no.1: 69-81.

Mason, R. (2006). Learning Technologies for Adult Continuing Education. Studies in Continuing Education, 28:2 121-133.

Jackson, Linda A (2006) Does Home Internet Use Influence the Academic Performance of Low-Income Children? Developmental Psychology Copyright 2006 by the American Psychological Association 2006, Vol. 42, No. 3, $429-435$

Joinson, A. N. (2008). Looking at, looking up or keeping up with people? Motives and use of Facebook. Paper presented at the 26th annual SIGCHI conference on Human Factors in Computing Systems, Florence, Italy.

Golder, S. A., Wilkinson, D., \& Huberman, B. A. (2007). Rhythms of social interaction: messaging within a massive online network: 3rd International Conference on Communities and Technologies 